\title{
Extrapolating the Trends of Test Drop Data with Opening Shock Factor Calculations: the Case of the Orion Main and Drogue Parachutes Inflating to $1^{\text {st }}$ Reefed Stage
}

\author{
Jean Potvin ${ }^{1}$ \\ Saint Louis University, St. Louis, MO 63103 \\ and \\ Eric Ray ${ }^{2}$ \\ MRI Technologies (JETS), Houston, TX, 77058
}

\begin{abstract}
We describe a new calculation of the opening shock factor $C_{k}$ characterizing the inflation performance of NASA's Orion spacecraft main and drogue parachutes opening under a reefing constraint ( $1^{\text {st }}$ stage reefing), as currently tested in the Capsule Parachute Assembly System (CPAS) program. This calculation is based on an application of the Momentum-Impulse Theorem at low mass ratio $\left(R_{m}<10^{-1}\right)$ and on an earlier analysis of the opening performance of drogues decelerating point masses and inflating along horizontal trajectories. Herein we extend the reach of the Theorem to include the effects of payload drag and gravitational impulse during near-vertical motion - both important pre-requisites for CPAS parachute analysis. The result is a family of $C_{k}$ versus $\boldsymbol{R}_{m}$ curves which can be used for extrapolating beyond the drop-tested envelope. The paper proves this claim in the case of the CPAS Mains and Drogues opening while trailing either a Parachute Compartment Drop Test Vehicle or a Parachute Test Vehicle (an Orion capsule boiler plate). It is seen that in all cases the values of the opening shock factor can be extrapolated over a range in mass ratio that is at least twice that of the test drop data.
\end{abstract}

\section{Nomenclature}

$C_{D 0} \quad=$ drag coefficient based on the nominal diameter

$C_{k} \quad=$ opening shock factor measured at arbitrary $R_{m}$

$C_{Z} \quad=$ Ratio of the specific momentum over fill time

$D_{0} \quad=$ nominal diameter

$D_{\text {ref }} \quad=$ reference diameter $\left(=\left(\varepsilon_{l}\right)^{1 / 2} D_{0}\right.$ during $1^{\text {st }}$ stage inflation $)$

$d t \quad=$ integration time increment

$F_{D}(t) \quad=$ drag force

$F_{\max }$

$=$ maximum drag sustained during inflation

$F_{D}^{\text {loadbody }}(t)=$ drag force of the payload (forebody), per cluster member, at time $t$

$g \quad=$ constant of gravitational acceleration

$H \quad=$ inflation time ratio (defined in [5])

$I \quad=$ parachute drag integral (Eq. 15; also labeled as $I_{\text {chute }}$ )

$I_{\text {forebody }} \quad=$ drag integral of the payload (per cluster member)

$J(Z) \quad=$ new scaling function; defined as equal to $C_{k} / C_{X}$

$k_{V} \quad=$ specific momentum (defined in [5])

$m_{\text {air }} \quad=$ estimated mass of the air co-moving with an inflating parachute

$m_{\text {total }} \quad=$ mass of the payload shared by each cluster member

$M_{\text {total }}=$ total mass of the parachutes and payload

$n_{\text {fill }} \quad=$ non-dimensional filling time

PCDTV $\quad=$ Parachute Compartment Drop Test Vehicle (dart shaped)

PTV $\quad=$ Parachute Test Vehicle (Orion capsule boilerplate)

$R_{m} \quad=$ mass ratio

\footnotetext{
${ }^{1}$ Professor, Department of Physics, 3511 Laclede Ave., and AIAA Associate Fellow.

${ }^{2}$ Analysis Engineer, Aerosciences, Flight Dynamics and GN\&C, 2224 Bay Area Blvd, Houston, TX, AIAA Senior Member.
} 


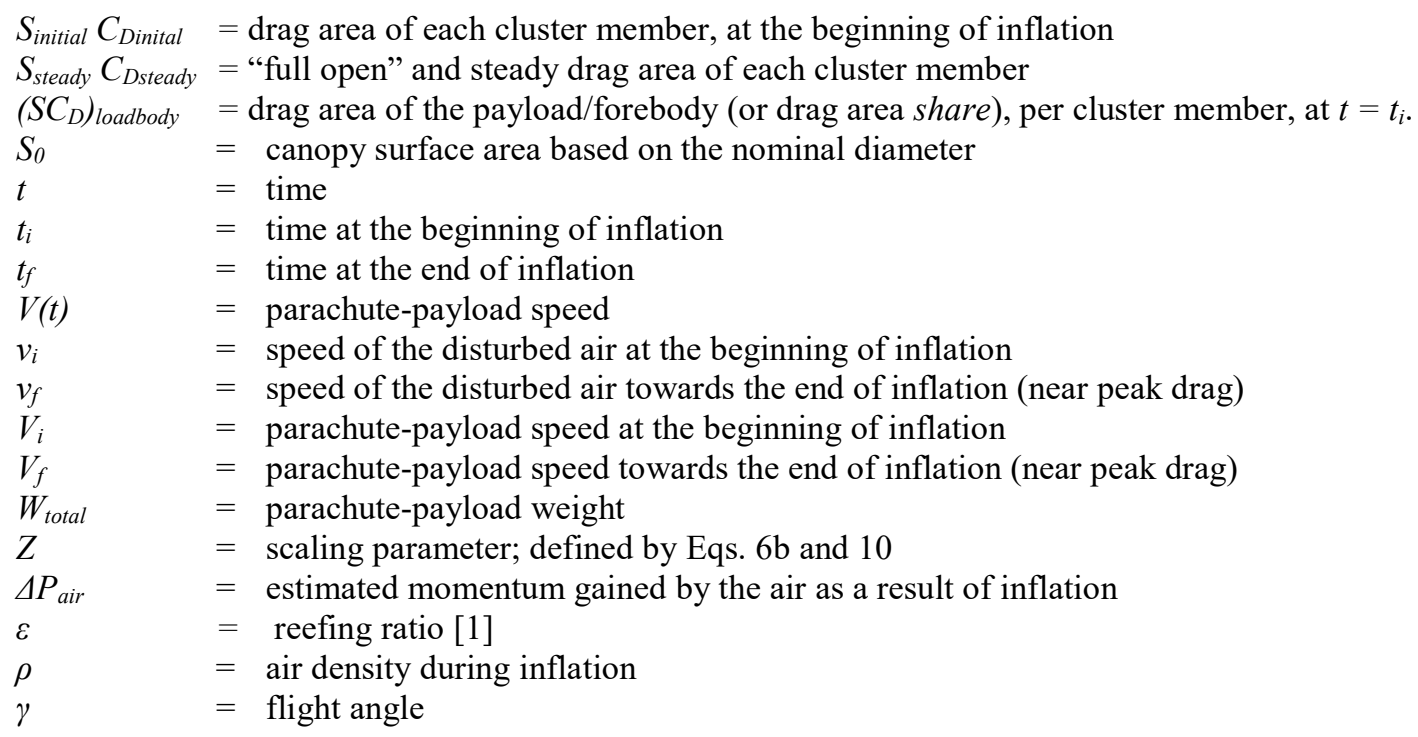

\section{Introduction}

Q STIMATION of the peak force sustained by inflating parachutes can be carried out with the use of the opening shock factor $C_{k}[1,2]$, a dimensionless force ratio which collapses test data within an easily identifiable band when plotted against the mass ratio $R_{m}[1,2]$ (Fig. 1). Being able to predict the value of $C_{k}$ at any mass ratios allows for a prediction of peak loads in cases where test data is unavailable, or when the operational envelope is being extended beyond the parameters of a previous test program. Estimating the opening shock factor has been for the most part an empirical affair. On the other hand, calculating $C_{k}$ from theory is more difficult given the large number of design and dynamical parameters that may be in play. Theoretical investigation may be worth the effort, however, since it allows design and test engineers to extend, via physically-justified extrapolations, the values of $C_{k}$ that have been obtained empirically [3-5]. Such extrapolation schemes have been proposed in the past, i.e., for landing parachutes which operate at large mass ratios $\left(R_{m}>1\right)[3,4]$, and horizontally-opening drogue parachutes which operate at small mass ratios $\left(R_{m}<10^{-1}\right)$ [5]. The main goal of this paper is to show how similar extrapolations can be obtained in the case of Orion-CPAS parachute systems, specifically for both Drogues and Mains opening while reefed ( $1^{\text {st }}$ reef Stage inflation) $[6,7]$, in the hopes of extrapolating the reach of test drop data to a significantly wider range of mass ratios, as shown in figures 7 - 9 below. For large government R\&D programs like CPAS where parachute performance simulation and prediction tools already exist [8,9], such trend expansion calculations provide a sanity check or confirming evidence, in the form of an alternate forecast platform based on different sets of physical approximations and assumptions.

Reefed CPAS parachutes inflate at small mass ratios (Fig. 1), but in the process decelerate draggy payloads while falling along a near-vertical trajectory. This calls for non-trivial extensions of the formalism discussed in [5], which so far has been applied to point payload masses decelerating along the horizontal. As will be shown here, the effects of the gravitational impulse are important for both main and drogue parachutes as both are characterized by largeenough inverse-Froude numbers. Herein, these new extensions are presented first, followed by a prescription for calculating meaningful $C_{k}$-extrapolations beyond the test drop mass ratios, i.e., while using small subsets of the entire CPAS test database. These opening shock factor extrapolations are constructed for several cases, including the opening of the CPAS Mains and Drogue canopies decelerating the Parachute Compartment Drop Test Vehicle (or PCDTV) or the Orion capsule boiler plate (Parachute Test Vehicle - PTV) shown in figure 2.

\section{Mathematical Details}

\section{A. Opening shock factor $\boldsymbol{C}_{\boldsymbol{k}}$ basics for clusters}

Knowing the value of $C_{k}$ allows for the computation of peak loads $\left(F_{\max }\right)$ from a simple equation, namely [1, 2],

$$
F_{\max }=\left(\frac{1}{2} \rho V_{i}^{2}\right)\left(S_{\text {steady }} C_{\text {Dsteady }}\right) \cdot C_{k}
$$


with $V_{i}$ corresponding to the parachute-payload speed at the beginning of inflation (at line-stretch, typically), and $S_{\text {steady }} C_{\text {Dsteady }}$ to the steady state parachute drag area post- inflation (post $1^{\text {st }}$ stage inflation or unreefed inflation). The one interesting property of $C_{k}$ is its strong dependence on the mass ratio $\left(R_{m}\right)$ shown in figure 1 , with the latter defined as

$$
R_{m} \equiv \frac{\rho\left(S_{\text {steady }} C_{\text {Dsteady }}\right)^{3 / 2}}{m_{\text {total }}}
$$

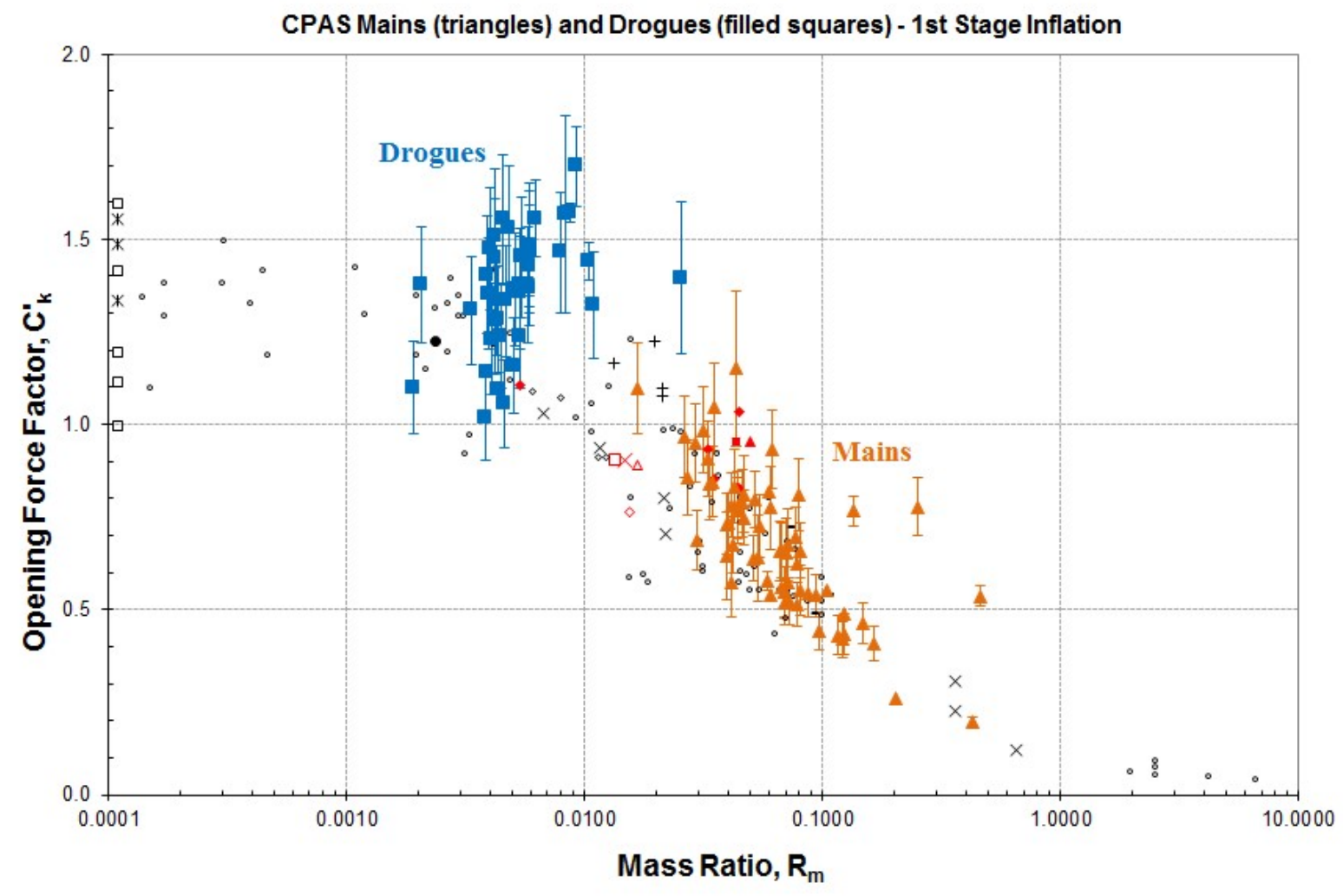

Figure 1. Opening shock factor by each Main parachute (orange triangles) and Drogue parachute (blue squares) of the CPAS EDU program, deployed in either 3- or 2-clusters, while inflating during $1^{\text {st }}$ stage reefing. The CPAS data is superposed to Wolf's compilation obtained with non-clustered parachutes (all black symbols) [2]. The mass ratio for the CPAS cases is calculated with Eq. 3 in order to reflect the load share handled by each cluster-member.

In the case of single parachute systems, $m_{\text {tot }}$ is simply the total mass of the parachute-payload. In applications to clustered canopies, $F_{\max }$ and $m_{\text {total }}$ are interpreted as the peak drag sustained, and weight shared by each cluster member respectively. For peak drag, this is accomplished by using the steady ("full open") drag area value $\left(S_{\text {steady }} C_{D \text { steady }}\right)_{(i)}$ characterizing a specific cluster member (labeled " $i$ " here). For total mass, and for example in a 3cluster, the payload weight share is estimated from the (measured) drag areas of each cluster member as follows (for cluster-member \#2 as an example):

$$
m_{\text {total }}^{(2)} \equiv \frac{\left(S_{\text {steady }} C_{\text {Dsteady }}\right)_{(2)}}{\left(S_{\text {steady }} C_{\text {Dsteady }}\right)_{(1)}+\left(S_{\text {steady }} C_{\text {Dsteady }}\right)_{(2)}+\left(S_{\text {steady }} C_{\text {Dsteady }}\right)_{(3)}} M_{\text {total }}
$$

In this formulation, $M_{\text {total }}$ corresponds to the total mass of the cluster-payload system. Thus $m_{\text {total }}{ }^{(i)}=(1 / 3) M_{\text {total }}$ in 3-clusters generating equal load share. In the CPAS program, the Mains are used either in 3- or 2-cluster 
configurations and the Drogues in 2-clusters. With the exception of the next section (II.B), the drag forces and masses being discussed will always refer to those characterizing each specific member of a cluster.

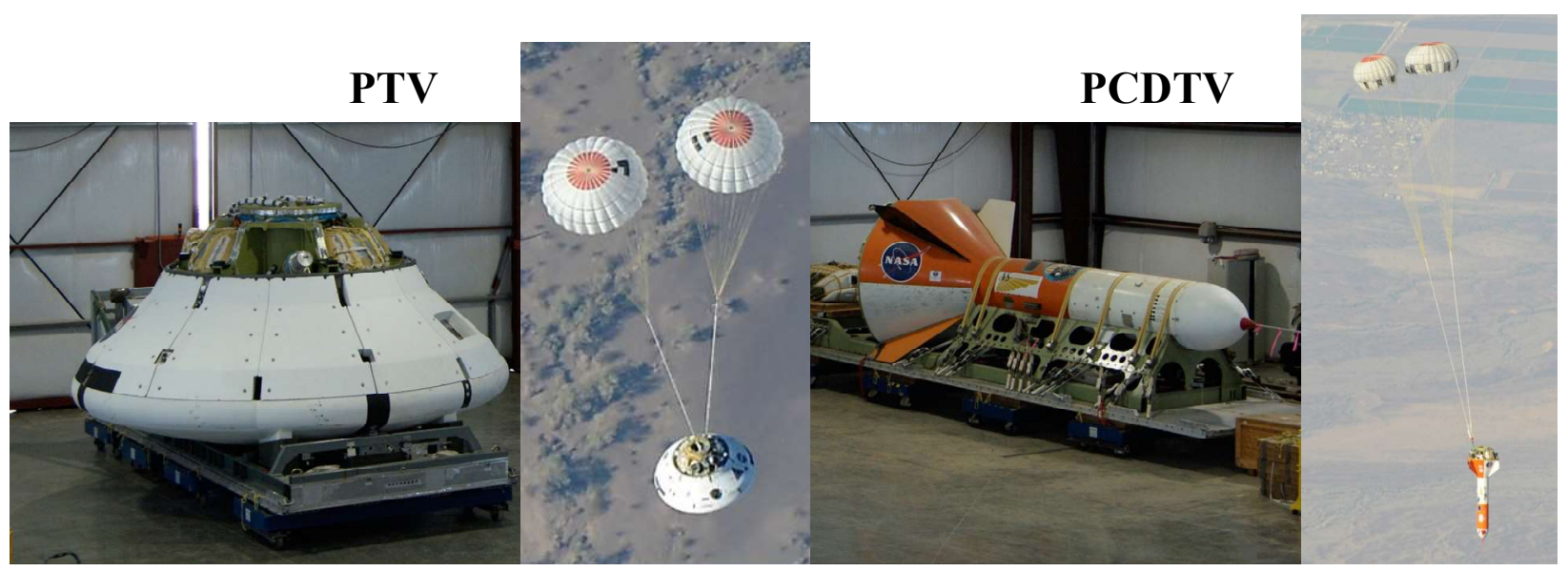

Figure 2. Orion capsule boiler plate (Parachute Test Vehicle - PTV) and the Parachute Compartment Drop Test Vehicle (or PCDTV).

\section{B. Single parachute decelerating a point mass along the horizontal [5]}

The fundamental principle behind the calculation of the opening shock factor is the well-known MomentumImpulse Theorem learned in introductory college physics. It is illustrated here in the case of a single parachute decelerating a dragless payload and inflating along the horizontal. The theorem is based on the time integral of the system's Newtonian equation(s) of motion and written as follows between the time of onset of inflation $\left(t_{i}\right)$ and the time near peak drag $\left(t_{f}\right)$ :

$$
m_{\text {total }} V_{f}-m_{\text {total }} V_{i}=-\int_{i}^{f} F_{D}(t) d t
$$

(Here $m_{\text {total }}=M_{\text {total }}$, trivially). This expression relates the momentum change of the parachute-payload system (during inflation) to the impulse generated by parachute drag $\left(F_{D}\right)$. A similar equation applies to the air that is set into motion by the inflating canopy [5]:

$$
m_{\text {air }} v_{\text {air }(f)}-m_{\text {air }} v_{\text {air }(i)} \equiv \Delta P_{\text {air }}=\int_{i}^{f} F_{D}(t) d t
$$

Symbolically $\Delta P_{\text {air }}$ represents the momentum gained, along the direction of the motion, by the air both externally and internally to the canopy, and turns out to be a crucial inflation parameter. Here the drag force is seen as the contact force between the parachute and the air itself. Note that the air does not sustain a gravitational impulse as it is cancelled by its own buoyancy. Note also that merging Eqs. $4 \mathrm{a}$ and $4 \mathrm{~b}$ yields momentum conservation, i.e., by expressing the momentum lost by the parachute-load in terms of the momentum gained by the disturbed air.

Equation $4 \mathrm{~b}$, together with Eqs. $1-3$ lead exactly to the following formula for the opening shock factor $C_{k}$ :

$$
C_{k}\left(R_{m}\right)=\left[\frac{2 \sqrt{S_{\text {steady }} C_{\text {Dsteady }}}}{D_{\text {ref }}} \frac{1}{I}\left(\frac{k_{V}}{n_{\text {fill }}}\right)\right]
$$

Parameter $n_{\text {fill }}$ is the standard fill time $\left(\equiv\left(t_{f}-t_{i}\right) V_{i} / D_{\text {ref }}\right)[1]$ and $I$ is defined as the integral of $F_{D}$ over time, divided by the peak drag times the inflation time - the so-called "drag integral" [3- 5]. In other words, $I$ is a measure of the shape of the drag-versus-time curve, yielding $I \sim 1 / 2$ when a canopy force-vs-time trace looks like a triangle, or $\sim 1$ when it looks like a rectangle (more examples are provided in [5] and also in [3, 4]). The so-called specific momentum $k_{V}$ is defined as $\Delta P_{\text {air }}$ (Eq. $\left.4 \mathrm{~b}\right)$ divided by the air momentum scale $\rho\left(S_{\text {steady }} C_{D \text { steady }}\right)^{3 / 2} V_{i}[5]$. 
What this formula shows is that $C_{k}$ depends on three dynamical variables, namely $k_{V}, n_{\text {fill }}$ and $I$, in addition to the two design-dependent variable $S_{\text {steady }} C_{D \text { steady }}$ and $D_{\text {ref. }}$. Thus calculating $C_{k}$ must begin with knowing the values of these dynamical parameters, which will depend not only on parachute design but also on the specific aerodynamics taking place during each inflation sequence. This sounds like an impediment - but perhaps not - if $k_{V}$ and $I$ scatter in manners similar to $n_{\text {fill }}$ on a drop-to-drop basis (for the same parachute system). Another important assumption will consider $k_{V}, n_{\text {fil }}$ and $I$ as independent variables, and ones that are also independent of the initial speed $V_{i}$. Because of this property, the ratio $k_{V} / n_{\text {fill }}$ will be used instead of $k_{V}$, owing to the fact that $C_{k}$ parameterizes a force which itself is a rate of momentum transfer - just like the ratio $k_{V} / n_{\text {fill }}$. For this reason the latter shall be relabeled as $\boldsymbol{C}_{\boldsymbol{Z}}\left(\equiv \boldsymbol{k}_{V} / \boldsymbol{n}_{\text {fill }}\right)$.

Although conceptually clearer, relating $C_{k}$ to a rate of momentum transfer $\left(C_{Z}\right)$ does not make equation $5 \mathrm{a}$ any more practical. Some empirical data is needed to make its use possible after all. Reference [5] shows that the following formulas could be used instead if wind tunnel or time-dependent Computational Fluid-Structure Interactions (FSI) data of the parachute system is available for determining $n_{\text {fill }}, I$ and $C_{Z}$ :

$$
C_{k}\left(R_{m}\right)=\left[\frac{2 \sqrt{S_{\text {steady }} C_{\text {Dsteady }}}}{D_{\text {ref }}} \frac{1}{I^{(w t)}} C_{Z}^{(w t)}\right] \cdot J(Z)
$$

where

and where [5]

$$
J(Z)=1-1.813 Z+1.6522 Z^{2}-0.4933 Z^{3}-0.1205 Z^{4} \quad,
$$

$$
Z=H n_{\text {fill }} C_{Z} R_{m}<0.8
$$

Input parameters $n_{f i l}{ }^{(w t)}, I^{(w t)}$ and $C_{Z}^{(w t)}$ correspond to those "wind tunnel" values of the non-dimensional variable introduced above. But other inputs are needed as well, including parameter $H$, defined as the fill time $n_{\text {fill }}$ of the canopy divided by the fill time of the same (and hypothetical) canopy built with zero geometric porosity [5]. As such this is a canopy geometry characteristic rather than an inflation dynamics characteristic and previous estimates have determined $H$ as $\sim 1$ for near-zero porosity canopies, $\sim 1.25$ for DGB-type canopies and $\sim 1.8$ for conical ribbon canopies [5]. It shall be shown below that $H \sim 0.5$ for ringsail types (CPAS Mains $1^{\text {st }}$ stage), most likely due to the sails bellowing outwards and scooping-in extra air in comparison to their un-vented and un-slotted counterparts (thereby speeding up inflation). $Z$ is a new scaling parameter that collapses all parachute peak load data - both low- and high-porosity data - onto a single line as shown in figure 3. Finally, note that assuming a four-term polynomial restricts the use of the above to inflation events occurring at small mass ratios, that is, to drogue-like parachutes.

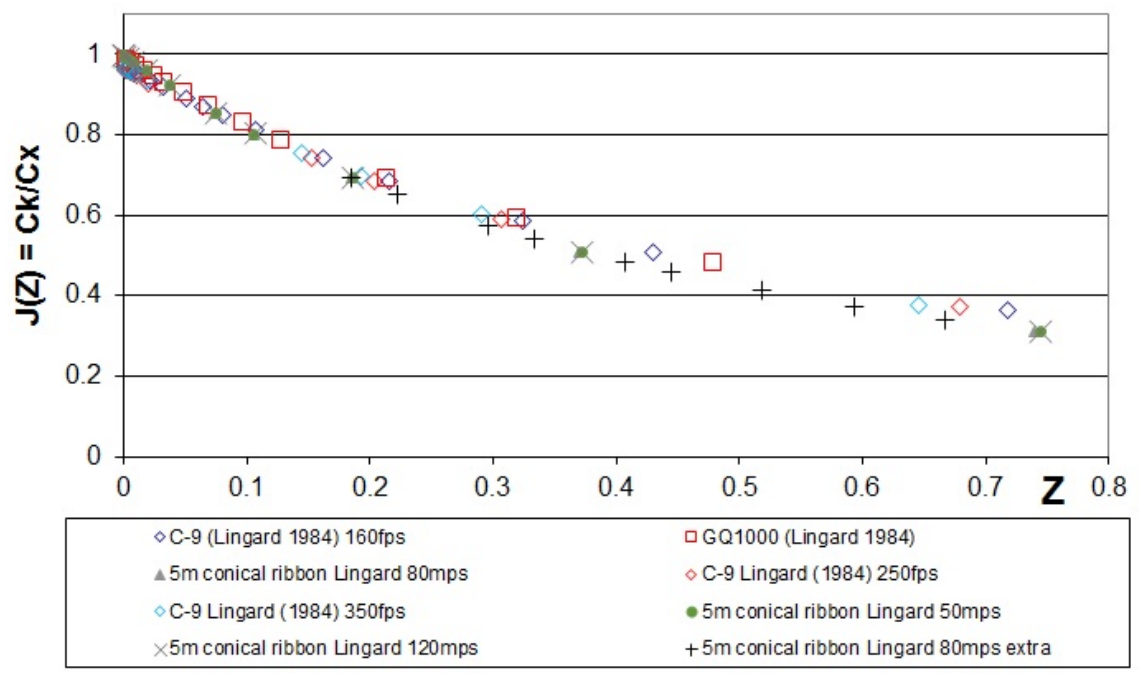

Figure 3. Universal function $\boldsymbol{J}(\boldsymbol{Z})$. Figure extracted from [5]. 
With $n_{f i l}{ }^{(w t)}, I^{(w t)}$ and $C_{Z}^{(w t)}$ thus collected and computed, Eqs. $5-6$ provide a scheme in which the opening shock factor can be predicted during drop testing, i.e., over the range of mass ratios where drogue parachutes operate. This is a practical approach but only to the extent that wind tunnel data is available for the system at hand. As this isn't the case with CPAS parachutes, a modification of the above is necessary, as further discussed in Section III.

\section{Dynamical inflation "profile" variables}

The Momentum-Impulse theorem makes clear that every inflation event is not only dependent on parachute design parameters such as $S_{\text {steady }} C_{D \text { steady, }}, D_{\text {ref }}$, and $H$, but also on the values of the dynamical opening profile variables $n_{\text {fill, }} I$ and $C_{Z}$. Like $n_{\text {fill }}[10]$ both $I$ and $C_{Z}$ are expected to vary on a drop-to-drop basis - albeit around a well-defined mean - for a given parachute-payload system, even when dropped at the same altitude and line-stretch velocity. At the root of such variations are the (small) random fluid-structure interactions that affect a canopy's instant shape, the flows of air that open it, and finally the amount of momentum the canopy transfers to the air. Such variations and randomizing processes are also expected to occur in wind tunnel investigations, to yield different sets of $n_{f i l}{ }^{(w t)}, I^{(w t)}$ and $C_{Z^{(w t)}}$-values on a (tunnel) run-to-run basis. To the extent that these random fluid-structure interactions are similar in both wind tunnel and test drop environments, it should be clear that equations 5 - 6 would yield not just one extrapolation (vs. $R_{m}$ ) but several, based on the different sets that can occur. Thus each set represent one opening "profile" of a given inflation event, out of a large number of possible profiles. Similarly, one curve calculated via Eqs. 5- 6 from one such set would represent an extrapolation for that one profile only.

\section{Decelerating a draggy payload along the near-vertical}

The analysis discussed so far [5] has neglected the influence of payload drag, in addition to assuming the parachute-load system following a purely horizontal trajectory. This contrasts with the CPAS and Orion cases which involve payloads that generate substantial drag while falling along a near-vertical trajectory. Such factors are important here as payload drag dissipate a fraction of the system's initial kinetic energy that would have otherwise gone into the energy of the fluid flows that open a parachute. On the other hand, and by pulling the payloadparachute system downward over a significant amount of time, gravity provides an extra source of energy that can be transferred into the energy of those same inflation flows. Thus the interplay between the two effects must be accounted as follows, per the MI theorem and for each cluster member:

$$
\begin{gathered}
m_{\text {total }} V_{f}-m_{\text {total }} V_{i}=-\int_{i}^{f} F_{D}^{\text {chute }}(t) d t-\int_{i}^{f} F_{D}^{\text {loadbody }}(t) d t+\left[m_{\text {total }} g\langle\cos \gamma\rangle\left(t_{f}-t_{f}\right)\right] \\
P_{\text {air }}=\int_{i}^{f} F_{D}^{\text {chute }}(t) d t+\int_{i}^{f} F_{D}^{\text {loadbody }}(t) d t
\end{gathered}
$$

In the above the function $F_{D}$ loadbody corresponds to payload/forebody drag per cluster member, calculated according to each cluster member's load share in the steady full-open state (i.e., calculated via Eq. 3, with the masses replaced by the drag forces). On the other hand, the factor in between the square brackets corresponds to the gravitational impulse. Generally, the presence of the latter increases the value of $C_{k}$ [3]. Assuming little change of flight angle $(\gamma)$ during inflation, the factor $<\cos \gamma>$ becomes the average cosine of the flight angle. For example, and by convention, $<\cos \gamma>=0$ for strictly horizontal motion, and $=1$ for strictly vertical motion. Note that behind Eq. 7 is also the assumption of the system's total drag being broken down into non-directly-interacting parachute and payload components. Finally, merging equations $7 \mathrm{a}$ and $7 \mathrm{~b}$ now yields an expression of a parachute-payload's momentum change during inflation written in terms of the momentum lost to the air and the momentum gained from the gravitational impulse.

Starting from Eq. 7b while using Eqs. 1-3, and again after assuming the availability of wind tunnel data, one obtains the following:

$$
C_{k}\left(R_{m}\right)=\left[\left(\frac{2 \sqrt{\left.S_{\text {steady }} C_{\text {Dsteady }}\right|_{\text {chute }}}}{D_{\text {ref }}} \frac{C_{Z}^{(w t)}}{I^{(w t)}}\right)-\left(\frac{\left.S C_{D}\right|_{\text {loadbody }}}{\left.S_{\text {steady }} C_{\text {Dsteady }}\right|_{\text {chute }}} \frac{\left.I^{(w t)}\right|_{\text {loadbody }}}{\left.I^{(w t)}\right|_{\text {chute }}}\right)\right] \cdot J(Z)
$$




$$
\begin{gathered}
J(Z)=1-1.813 Z+1.6522 Z^{2}-0.4933 Z^{3}-0.1205 Z^{4} \\
Z=H n_{\text {fil }} \cdot\left[C_{Z}{ }^{(w t)} R_{m}-\frac{g D_{r e f}}{V_{i}^{2}}\langle\cos \gamma\rangle\right]
\end{gathered}
$$

The parameters connected to the parachute (labeled as "chute") are the same as in Section II.B. But now one has the initial payload drag area share $\left(S C_{D}\right)_{\text {loadbody }}$ (at $\left.t=t_{i}\right)$ to characterize and calculated from a procedure similar to Eq. 3, as well as the payload drag integral defined by

$$
I_{\text {loadbody }}=\int_{i}^{f} \frac{\left|F_{D}^{\text {loadbody }}(t)\right|}{\left(1 / 2 \rho\left(S C_{D}\right)_{\text {loadbody }} V_{i}^{2}\right) \cdot t_{\text {fill }}} d t
$$

Both inputs are available from CPAS data. On the other hand, the effects of the gravitational impulse appear as the second term in Eq. 10 involving the inverse Froude factor $g D_{\text {ref }} / V_{i}^{2}$. With parachutes typically starting to inflate at $V_{i} \sim 200 \mathrm{ft} / \mathrm{s}$, the ratio $g D_{\text {ref }} / V_{i}^{2}$ becomes important only when the reference diameter is large enough: namely, $g D_{\text {ref }} / V_{i}^{2} \sim 0.09$ (CPAS Mains) versus $\sim 0.02$ (CPAS Drogues). We note that considering draggy payloads hereby adds two new dynamical variables, namely $\left(S C_{D}\right)_{\text {loadbody }}$ and $I_{\text {loadbody }}$, to the trio $n_{\text {fill }}, I$ and $C_{Z}$ that characterizes a parachute's opening profile. These will be assumed to disperse on a drop-to-drop basis in manners similar to $n_{\text {fill }}$.

We note that equation 8 re-defines what is meant by "wind tunnel" values: namely, the values of $n_{\text {fill }} I$ and $C_{Z}$ that one would measure at $\mathrm{Z}=0$. With horizontally-opening parachutes the point $\mathrm{Z}=0$ corresponds to $R_{m}=0$, the case where the airspeed is nearly constant during inflation and thus relevant to wind tunnel study. The term "wind tunnel" is somewhat misleading in CPAS applications since the payload weights at hand and vertical trajectories used will cause the parachute-load system to decelerate or accelerate at times (accelerating especially at the beginning of inflation). From Eq. 10 the mass ratio corresponding to the point $Z=0$ is given by

$$
R_{m}{ }^{\mathrm{Z}=0}=\frac{g D_{\text {ref }}}{C_{Z}^{\left({ }^{(w t)} V_{i}{ }^{2}\right.}}\langle\cos \gamma\rangle
$$

which for a CPAS main parachute would correspond to $R_{m}{ }^{Z=0} \sim 0.06$, i.e., a case involving a deceleration. Generally, actual wind tunnel studies being performed at constant airspeed will not correspond to $R_{m}{ }^{Z=0}$ if the system is to accelerate during a test drop at that value of the mass ratio. Rather, such a wind tunnel test would correspond to a mass ratio where $Z \neq 0$ and estimated as follows:

$$
R_{m}{ }^{\text {const-V }}=\frac{S_{\text {initial }} C_{D \text { initial }}}{S_{\text {steady }} C_{D \text { steady }}} \cdot \frac{g D_{\text {ref }}}{C_{Z}{ }^{(w t)} V_{i}^{2}}\langle\cos \gamma\rangle,
$$

with the factor $S_{\text {initial }} C_{\text {Dinitial }}$ corresponding to parachute initial drag area. Further discussion on using wind tunnel data for CPAS parachutes is postponed to Section V.B. In the meantime, properly eliminating the confusion is simply done by replacing all " $w t$ " superscripts in Eqs. 5, 8 and 13 (below) with " $Z=0$ " superscripts.

Two important distinctions are to be pointed out when comparing Eqs. $5 \mathrm{~b}$ and 8: First that $C_{Z}$ in the former is the rate of momentum transferred (to the air) by the parachute only, as the payload contributed no drag on its own; versus the latter, where $C_{Z}$ is again the rate of momentum acquired by the air, but this time as transferred by both parachute and payload. The second distinction is the appearance of a new term in the definition of $Z$ in Eq. 10 due to the gravitational impulse (compare with Eq. 6b). In both cases $Z$ is a measure of deceleration by the system, as evaluated by the ratio of the added mass drag to the system's total drag [5]. But CPAS add another element, namely the possibility of accelerated trajectories during inflation, which in turns will lead to negative values of $Z$. With the function $J(Z)$ (Eq.9) obtained from a decelerating parachute database [5] and therefore constructed for positive values of $Z$, using equation 9 where $Z$ is negative becomes an assumption. This, however, can be justified if one envisages $J(Z)$ being continuous in both values and slope across $Z=0$, thereby lending Eq. 9 some validity at small negative $Z$. As shown below, CPAS data indeed exhibit such values over all cases analyzed $(-0.08<\mathrm{Z}<0.30)$. 


\section{Reconstructing the "wt" (or " $Z=0$ ") Inputs with Test Drop Data}

\section{A. Linearization of the $J(Z)$ polynomial}

At first sight, it would appear that such a wind tunnel-based scheme would be of little use for development programs of large-size parachutes in which wind tunnel data is unavailable - as with CPAS. However, CPAS is a program that has generated a very large and high-quality test drop database, which in turns may be used to reconstruct the " $w t^{\prime}$ " (or " $Z=0$ ") parameter set $n_{\text {fill }}{ }^{(w t)}, I^{(w t)}$ and $C_{Z}(w t)$. This is possible, particularly in the case of the drogues and mains opening during $1^{\text {st }}$-stage reefing, being characterized by small values of the mass ratio (Figure 1 ). This, along with $C_{Z}$ having the upper bound $\mathrm{C}_{Z}<0.68 / \mathrm{C}_{\mathrm{D}}^{3 / 2}<1$, allows approximating $J(Z)$ as $J(Z) \sim 1-1.813 Z$ (see Eq. 9), which when inserted in Eqs. 8 -10 yields:

$$
\begin{aligned}
& C_{k}\left(R_{m}\right)=\left[\left(\frac{2 \sqrt{\left.S_{\text {steady }} C_{\text {Dsteady }}\right|_{\text {chute }}}}{D_{\text {ref }}} \frac{C_{Z}^{(w t)}}{I^{(w t)}}\right)-\left(\frac{\left.S_{\text {steady }} C_{D_{\text {steady }} \mid}\right|_{\text {loadbody }}}{\left.S_{\text {steady }} C_{D_{\text {steady }}}\right|_{\text {chute }}} \frac{\left.I^{(w t)}\right|_{\text {loadbody }}}{\left.I^{(w t)}\right|_{\text {chute }}}\right)\right] . \\
&\left\{1-1.813 H n_{\text {fill }} \cdot\left[C_{Z}{ }^{(w t)} R_{m}-n_{\text {fill }} \frac{g D_{\text {ref }}}{V_{i}^{2}}\langle\cos \gamma\rangle\right]\right\}
\end{aligned}
$$

Eq. 13 is a $2^{\text {nd }}$ order algebraic equation in $C_{Z}^{(w t)}$ yielding a solution once a subset of CPAS data has been used to supply the inputs $R_{m}, C_{k}\left(R_{m}\right), n_{\text {fill }}{ }^{(w t)}$ and $I^{(w t)}$ (as described next). With these "wind tunnel" values thus reconstructed, an extrapolation of $C_{k}$ versus $R_{m}$ is obtained via the use of Eqs. 8 and 10, as well as with Eq. 9 then including all five terms.

\section{B. The reconstruction process}

This process is performed by first collecting a subset of test drop data corresponding to a given cluster member (i.e., parachute serial number) and to a given test drop. Such data has to include $V_{i}, S_{\text {steady }} C_{\text {steady }}, D_{\text {ref, }}, n_{\text {fill }}, R_{m}$ (via Eq. 3) and the average flight angle $<\cos \gamma>$. Moreover, the drop's $F_{D^{-}}$-versus-time curve yields the peak drag and fill time, which along with knowing $V_{i}$ and $S_{\text {steady }} C_{D \text { steady }}$, produces values for $C_{k}$. Following [11, 12], the fill time obtained from the test drop is assumed as being the same as $n_{\text {fill }}{ }^{(w t)}$. Following [1], the value of $D_{\text {ref }}$ is that of the parachute's nominal diameter $\left(D_{0}=116 \mathrm{ft}\right.$ for the Mains and $23 \mathrm{ft}$ for the Drogues), multiplied the by the square root of the (known) reefing ratio $\varepsilon_{1}$.

Parameter $H$ is defined as the fill time $n_{\text {fill }}$ of the canopy (here under the $1^{\text {st }}$ stage reefing constraint), over the fill time of the same (and hypothetical) canopy built at zero geometric porosity [5]. Previous estimates have determined $H \sim 1$ for near-zero porosity canopies, $H \sim 1.25$ for DGB-type canopies and $H \sim 1.8$ for conical ribbon canopies [5]. According to reference [1] (Table 5-6), ringsail parachutes reefed at diameter reefing ratio $\tau \sim 11 \%$ have fill constants of $n_{\text {fill }} \sim 7-8$. An equivalent low-porosity canopy could be (roughly) a T-10 reefed at $\tau \sim 10 \%$ which features of $\mathrm{n}_{\text {fill }} \sim 16-18$. This comparison would thus point to $H \sim 0.5$ given that $\varepsilon_{1} \sim \tau$ [1] and this is the value used in this analysis.

The drag integral $I$ is obtained from calculating the area under the drag versus time curve via the formula [3-5]:

$$
I_{\text {chute }} \equiv \int_{i}^{f} \frac{F_{D}^{\text {chute }}(t) d t}{F_{\max } t_{\text {fill }}}=\int_{i}^{f} \frac{\left(S C_{D}\right)_{(t)} q(t) d t}{F_{\max } t_{\text {fill }}}
$$

An important detail is the fact that during a typical drop the system may accelerate or decelerates somewhat, with the result that peak drag may be higher or lower than would occur in a no-deceleration case (Figure 4). It follows that the drag integral calculated from Eq. 14 isn't necessarily equal to $I_{\text {chute }}{ }^{(w t)}$. Given that the decelerations are small in relation to $g D_{\text {ref }} / V_{i}^{2}$ it is reasonable to assume $I_{\text {chute }}{ }^{(w t)}$ to be calculated from the time-dependent drop test drag area but corrected as follows: $F_{D}=\left(S C_{D}\right)_{t} q(t) \rightarrow\left(S C_{D}\right)_{t} q(0)=F_{D}$ corr , with $q(0)$ being equal to the dynamic pressure at line stretch. This results in the following "corrected" or "adjusted" drag integral:

$$
I_{\text {chute }}{ }^{(w t)} \sim \int_{i}^{f} \frac{q(0)\left(S C_{D}\right)_{(t)} d t}{F_{\max } t_{\text {fill }}}
$$


Figures 4 and 5 show examples of $F_{D}$ and $F_{D}{ }^{\text {corr }}$ evolving through inflation (the figures also list the corresponding values of the drag integral calculated via Eqs. 14 and 15). Note that the case shown in Figure 4 isn't decelerating as much as the case of Figure 5. In general, a drag-versus-time curve that is nearly triangular features a drag integral nearing $1 / 2$.

Finally, the CPAS data stream also provides information on the magnitude and time variations of payload drag $\left(F_{D}^{f o r e b o d y}\right)$ (Eq. 7a). This yields the payload's drag area as well as the drag integral defined in Eq. 11. Note that in the case of CPAS Mains using the PCDTV, shares of payload drag are very small in comparison to parachute drag area and sometimes allows for neglecting the term in $I_{\text {loadbody }}{ }^{(w t)}$ in Eq. 13.

Solving equation 13 for $C_{Z}^{(w t)}$ then completes the reconstruction process and provides, via equations $8-11$ a $C_{k}-$ versus- $R_{m}$ curve from which extrapolations can be carried out. Repeating this process over a subset of drops will provide different sets of $n_{f i l}{ }^{(w t)}, I^{(w t)}$ and $C_{Z}^{(w t)}$-values, thereby corresponding to the different inflations opening profiles discussed in Section II.C. (Note that solving Eq. 13, a quadratic algebraic equation, yields two roots. The negative root was picked for the lower $C_{Z}$-value which in turns yielded the smaller value for $Z$ (Eq. 10), thereby further justifying the use of the linearized version of $J(Z)$ ) in Eq. 13.
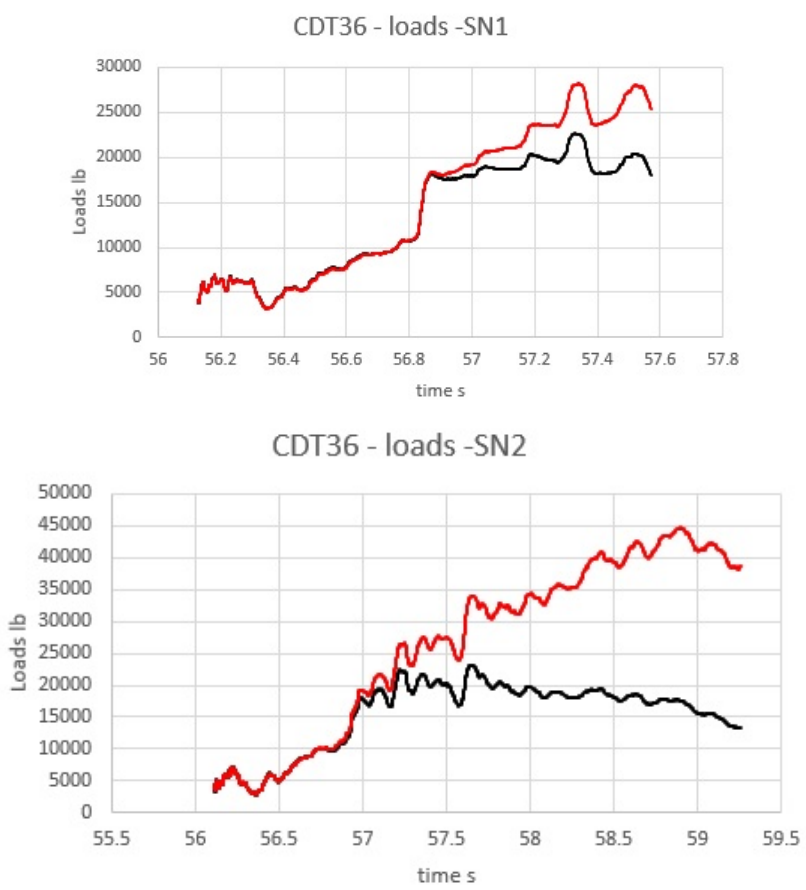

CDT36 - loads -SN3

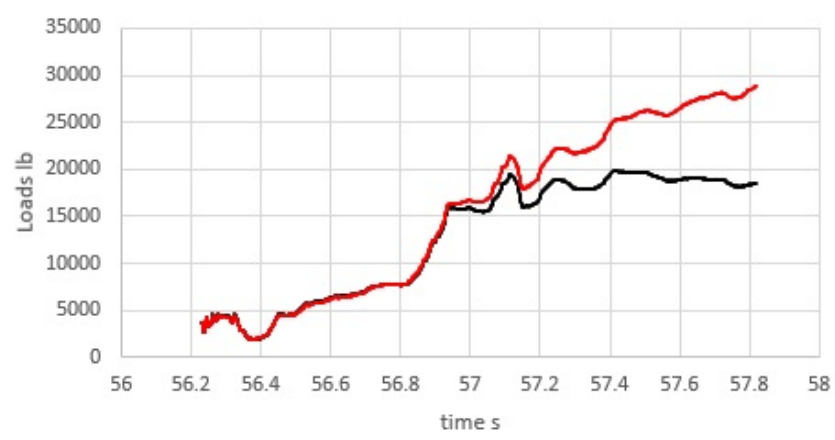

Figure 4. Raw drag (black; $\left.=\left(S_{D}\right)_{t} q(t)\right)$ and corrected drag $\left(\right.$ red; $\left.=\left(S_{D}\right)_{t} q(0)\right)$ versus time for CDT-3-6 (Mains $1^{\text {st }}$ stage). The corresponding drag integrals amount to: for SN1, 0.58 (Eq. 15) and 0.53 (Eq. 14); for SN2, 0.60 and 0.55 ; and for $\mathrm{SN} 3,0.65$ and 0.54 . In this analysis, inflation begins right after the first snatch peak, and ends soon after $S C_{D}$ has reached a value approximating the measured steady-state drag area. The ensuing fill times tend to differ from the CPAS official fill time by 0.3 seconds or less. 

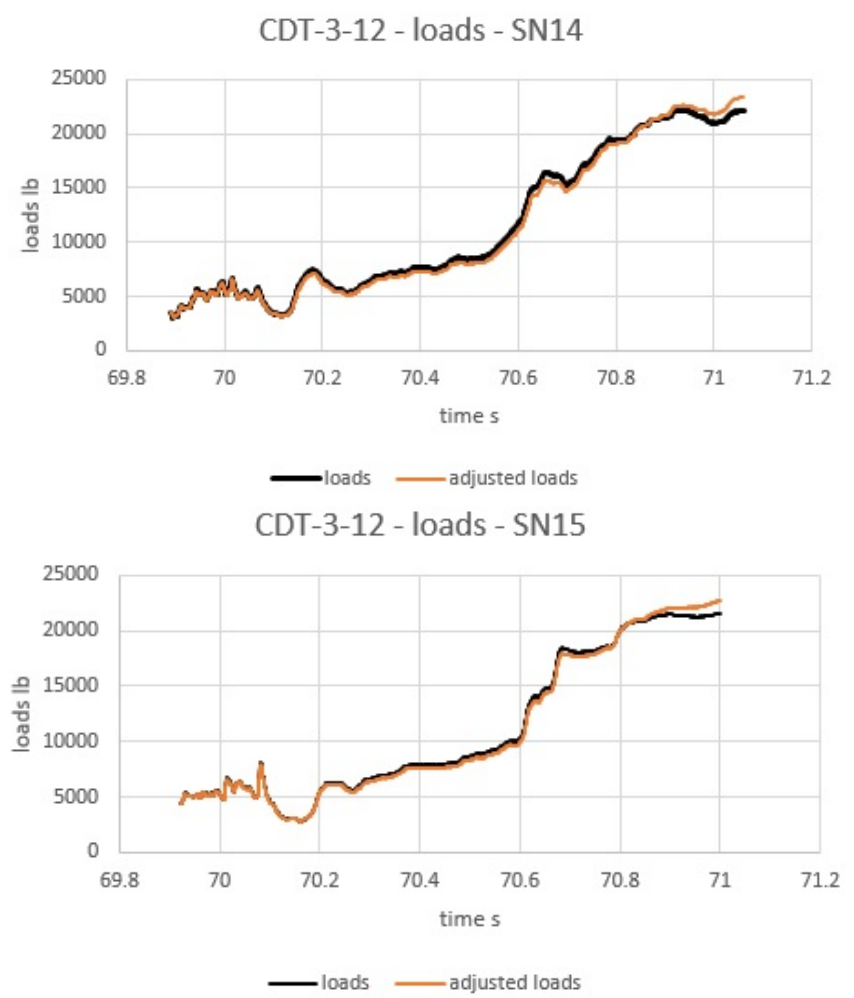

Figure 5. Raw drag (black) and corrected drag (red) versus time for CDT-3-12 (Mains $1^{\text {st }}$ stage). The corresponding drag integrals amount to: for SN14, 0.52 (Eq. 15) and 0.48 (Eq. 14); and for SN15, 0.42 and 0.49.

\section{Results}

At first sight, the inflation performance of all parachutes designs appears to follow a behavior in which $C_{k}$ plateaus to $C_{k} \sim 1.0-1.6$ at $R_{m}<0.001$ (see figure 1 and $[1,2,5]$ ), but decrease to fractions of these where $R_{m}>1.0$ (i.e., as $C_{k} \sim 1 / n_{\text {fill }} R_{m}[4,10]$ ). However, looking more closely at the data suggests that the exact manner in which this happens will depend quite strongly on the specifics of a parachute's design [5]. For example, low-porosity parachutes are to plateau to higher values of $C_{k}$, namely to $C_{k} \sim 1.6$ with 0.07 -geometric porosity canopies, in contrast to higher porosity parachutes which saturate at $C_{k} \sim 1.1-1.2$ at 0.30 -geometric porosity [13]. Another fundamental difference leading to a contrasting $C_{k}-R_{m}$-dependence is whether one considers unreefed or reefed inflation, versus disreefing inflation for which the data plateaus over a distinctively wider range of mass ratios [2]. Yet another design factor is the drag characteristics of the payload, which may or may not, affect significantly the location of the plateau at low $R_{m}$. For this reason the analysis below has been divided into four categories depending on the parachute and forebody types, namely: the Mains trailing the PTV or the PCDTV, and the Drogues trailing the PTV or the PCDTV.

\section{A. Example extrapolation}

Figure 6 shows an example of an extrapolation that can be achieved from the prescription described herein, while using the single data point of an inflating CPAS Main trailing a PCDTV during test drop CDT-3-4 (canopy SN5). The black continuous curve is built from the size, mass ratio and opening profile inputs listed in Table 1 (All tables appear at the very end of this paper). As measured and calculated from the data of test CDT-3-4, the fall speed $\left(V_{i}\right)$ at the beginning of inflation and inflation time $\left(\mathrm{n}_{\mathrm{fill}}\right)$ associated with this curve amount to $290.6 \mathrm{ft} / \mathrm{s}$ and 18.9 respectively. Extrapolation at high values of the mass ratio is cut-off at $R_{m}=0.1$ due to the unreliability of equations 6 and 9 beyond this point [5]. The black dashed and dot-dashed lines are further examples of extrapolations that can be made by changing the value of $V_{i}$ while keeping the opening profile variable the same. These examples suggest that the extrapolations from the test data located at $C_{k}=0.7$ at $R_{m}=0.0 .0758$ could rise or drop by less than $10 \%$ if the early inflation speeds are changed upwards or downwards by about $16 \%$; similar drops and rises are seen when 
the filling time $\left(\mathrm{n}_{\mathrm{fill}}\right)$ is changed by $30 \%$, as shown by the red extrapolation curves. Why such changes in extrapolation occur is described further in Section V.A.

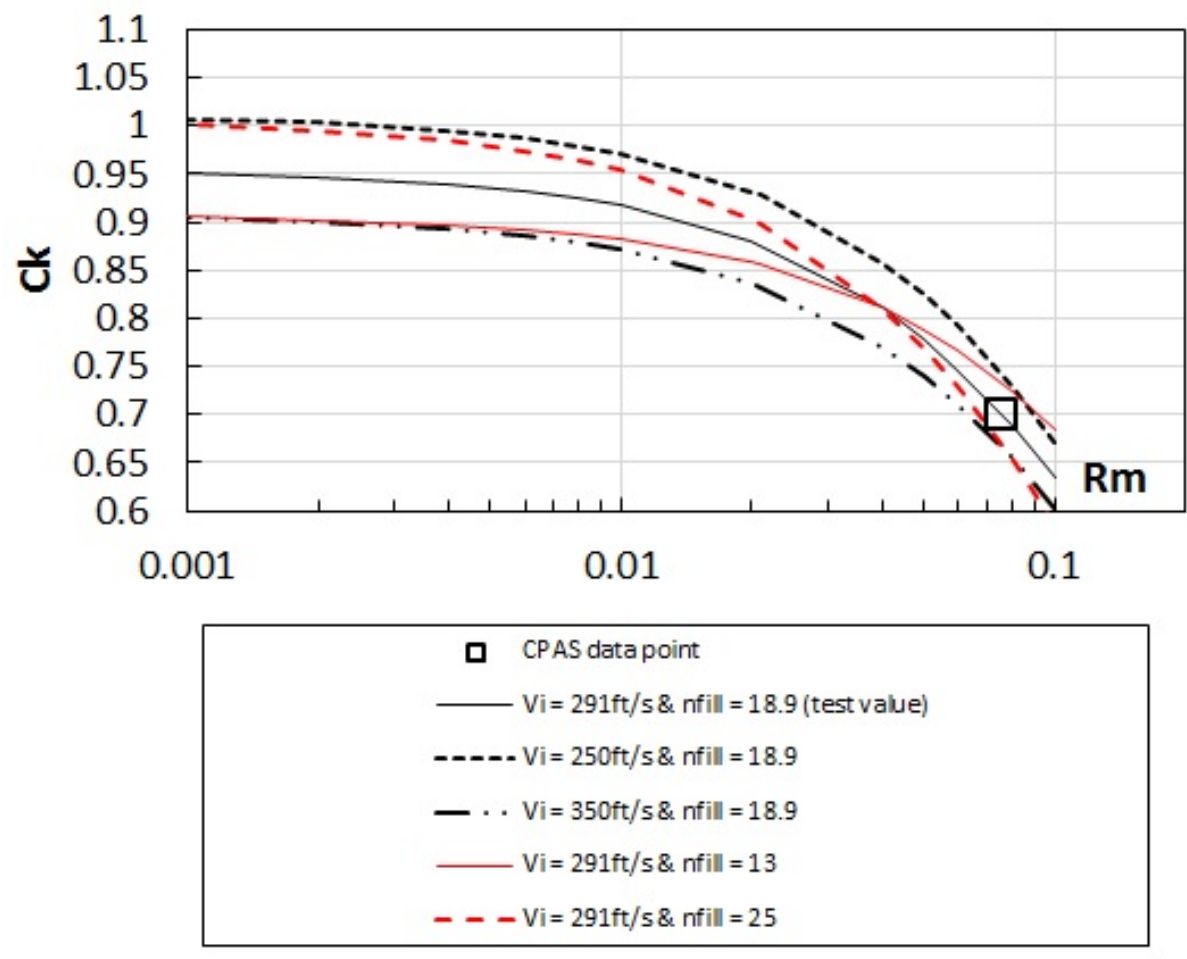

Figure 6. Opening shock factor extrapolation corresponding to CPAS Main SN5 inflating while trailing the PCDTV during test CDT-3-4. The continuous black extrapolation curve was reconstructed from the single data point shown (open square), per the use of equations 8-10. The black dashed and dot-dashed curves were calculated from the same equations and with the same inputs as CDT-3-4 SN5, but with a speed $V_{i}$ different from that of the test drop. Similarly, the red dashed and dot-dashed extrapolations correspond to the same data but with a filling time that is different from the measured value. The range of speeds and fill time used in the figure approximates the range seen in the CDT drops (Table 1).

\section{B. Mains $1^{\text {st }}$ stage inflation while trailing the PCDTV and PTV}

Table 1 and figure 7 show the results of the analysis for all but one PCDTV drops, with the mass ratio calculated for each cluster member via Eqs. 3, and inflation profile variables $n_{f i l}{ }^{(w t)}, I^{(w t)}$ and $C_{Z} Z^{(w t)}$ obtained from the procedure discussed in Section III.B. One notes the drop-to-drop values for $C_{Z}^{(w t)}$ and $I_{\text {chute }}{ }^{(w t)}$ clearly clustering around $C_{Z}{ }^{(w t)} \sim$ 0.25 and $I_{\text {chute }}{ }^{(w t)} \sim 0.50$, proving such concepts as meaningful for inflation analysis. These $C_{Z}{ }^{(w t)}$ 's are comparable to those of the (unreefed) parachutes discussed in reference [5] in the "drogue range" of mass ratios, namely (presumably all trailing small forebodies): USAF C-9 $C_{Z}^{(w t)} \sim 0.20$ (with $I_{\text {chute }}{ }^{(w t)} \sim 0.16$ ); GQ-1000 $C_{Z^{(w t)}}^{(w 0.15}$ $\left(I_{\text {chute }}{ }^{(w t)} \sim 0.22\right)$; five meter conical ribbon $C_{Z^{(w t)}} \sim 0.43\left(I_{\text {chute }}{ }^{(w t)} \sim 0.51\right)$; and MER DBG parachute $C_{Z}{ }^{(w t)} \sim 0.2-0.3$ $\left(I_{\text {chute }}{ }^{(w t)} \sim 0.20\right)$. Note finally that systems undergoing a lot of deceleration feature higher values of $Z$ (such as CDT3-6; figure 4) than those which decelerate less (such as CDT-3-12; figure 5). Also with CDT-3-6, $C_{Z}$ is likely to carry a larger error due to the linearized $J(Z)$ used here when $Z \sim 0.1-0.2$. Note that all extrapolation shown in the figure correspond to the fall speed $\left(V_{i}\right)$ and inflation time $\left(\mathrm{n}_{\text {fill }}\right)$ measured during the test data point shown (squares). Note also the differing trends shown at low- $\mathrm{R}_{\mathrm{m}}$, of the test data itself versus extrapolation. This issue is discussed further in Section V.A.

The table lists a couple of cases which have been deemed are unreliable, since the $C_{k}$ 's obtained from Eqs. 13 and those calculated with 8-10 then differed by over 5\% at the mass ratio value of the test drop. Both should yield identical results in order to be consistent with the idea of using Eq. 13 to re-construct the " $w t$ " (" $Z=0$ ") values of the opening profile variables on which the extrapolations Eqs. 8 - 11 depend. 
Table 2 and figure 8 show the same data type but for the Mains trailing the PTV. Comparing both tables and figures, the opening shock factors appear similar, a trend that is most likely due to payload drag (per parachute) being both small in comparison to the drag area of each parachute during most of the inflation sequence: namely, 30-50 $\mathrm{ft}^{2}$ payload drag area with the PCDTV and $\sim 50-100 \mathrm{ft}^{2}$ payload drag area with the PTV, versus $\sim 300-600$ $\mathrm{ft}^{2}$ for each canopy. On the other hand, the PTV data appear with a greater dispersion, possibly due to greater variation of capsule drag generated during the latter's wobbling in descent.

\section{Drogues $1^{\text {st }}$ stage inflation while trailing the PCDTV and PTV}

The input and calculated outputs for the drogues trailing the PCDTV and PTV are shown in Tables 3 and 4 respectively, and the opening shock extrapolations in figure 9 for both payloads. Note again that all extrapolation shown correspond to the fall speed $\left(V_{i}\right)$ and inflation time $\left(n_{\text {fill }}\right)$ measured during the test data point shown (triangles). Unlike the Mains, the Drogues' opening shock factors are significantly more sensitive to payload drag to the point of being easily noticeable in the figure, with the values of the PTV-based test being significantly lower. The difference also shows up quite clearly in the values of the of the specific air momentum ratio $C_{Z}$. Such sensitivity arises from the drogues' rated (full open) drag area being smaller than that of the Mains $\left(\sim 100-130 \mathrm{ft}^{2}\right.$; per Tables 3 and 4) but commensurate with the payload's shared drag area $\left(\sim 30-50 \mathrm{ft}^{2}\right.$ with the PCDTV and $\sim 50$ $120 \mathrm{ft}^{2}$ for the PTV). This is in agreement with the findings of reference [14]. Finally, the drogue data appear to plateau to higher opening shock factor values at small mass ratios than the $C_{k}$-extrapolations of the Mains shown in figures 7 and 8.

\section{Discussion}

\section{A. Meaning of the extrapolations}

Figure 7 shows an interesting pattern in which the test data (in the aggregate) appears to trend to higher values at $R_{m} \sim 0.01$ than suggested by the extrapolations. Many reasons could be behind this, including never having enough test data, which could lead to missing possible high- $\mathrm{C}_{\mathrm{k}}$ outlier points (compare with Fig. 8). Another explanation is that the curves shown were built with the early-inflation fall speed $\left(V_{i}\right)$ and inflation time $\left(n_{\text {fill }}\right)$ specific to a test drop data. By definition the values of $n_{\text {fill }}$ and $C_{Z}$ (via $\mathrm{k}_{\mathrm{V}}$ [5]) should be $V_{i}$-independent nominally (in other words, "independent to first order"), as a result of their definition carried out with a division by $V_{i}$ (see Section II); And so should the full-open parachute drag area. However, a residual $V_{i}$-dependence in the scaling parameter $Z$ remains, i.e., through the $1 / V_{i}^{2}$-factor appearing in the gravitational impulse term in equation 9 . The result is that calculating $C_{k}$ through Eqs. 8-10 will involve an additional (explicit) dependence on $V_{i}$ which will change the extrapolations if the value of $V_{i}$ is different from that of the original test data. The effect is shown in figure 6 where a higher $V_{i}$ increases the value of $\mathrm{Z}$ (a positive value) which in turns decrease $J(Z)$ and $C_{k}$. (Here increasing $V_{i}$ reduces the relative energetic contribution of the gravitational impulse to the energy of inflation). On the other hand, decreasing $V_{i}$ reduces $Z$ and increases $J(Z)$ and $C_{k}$. With drogues the effect is similar even though most are characterized by (small) negative values of $Z$, implying a dominance of the gravitational impulse term: A higher $V_{i}$ increases the value of $Z$ as it makes it less negative and smaller in absolute value, which again reduces $J(Z)$. (Where $Z<0$ we have used $J(Z) \sim 1+1.813|Z|$ (See Eq. 9)). Decreasing $V_{i}$ makes $Z$ more negative and greater in absolute value, thereby increasing $J(Z)$ and $C_{k}$. Such speed effects are noticeable in figure 6.

Using an inflation time value $n_{\text {fil }}$ different from the test-based value (but with the same initial speed and opening profile variables) will again affect the extrapolation through changes in Z (Fig. 6). Similarly, adjusting the initial forebody drag area share (and ratio $C_{Z}$ ) according to $V_{i}$ would effect changes as well. The main lesson here is that the extrapolations shown in figures $7-9$ will be changed somewhat if the speeds, inflation times and initial payload drag area share are changed from the original test data. The good news is that such changes can be evaluated and plotted using Eqs. 8 -10 again.

\section{B. Wind tunnel (or FSI) investigations of CPAS-type parachutes}

As briefly mentioned in Section II.D, the interpretation of wind tunnel or FSI data collected for parachutes used in vertical descent is different from using the same wind tunnel data of the same parachute but for applications involving horizontal inflation. With the latter this data would correspond to deployments carried out at zero mass ratio, while with the former $R_{m}$ would be calculated from Eq. 12b. Reconstructing the " $Z=0$ " (or " $w t$ ") values from Eq. 13 would proceed in similarity with the test drop cases of this paper, but with $\mathrm{Z}$ expressed as 


$$
Z=H n_{\text {fill }} \frac{g D_{r e f}}{V_{i}^{2}}\langle\cos \gamma\rangle \cdot\left[\frac{S_{\text {initial }} C_{D \text { initial }}}{S_{\text {steady }} C_{D \text { steady }}}-1\right] ;
$$

and used along with $C_{k}, I_{\text {chute }}{ }^{w t}, I_{\text {loadbody }}{ }^{w t}$, and $n_{\text {fill }}{ }^{\text {wt }}$ obtained from the wind tunnel/FSI data. In this exercise Eq. 13 is a linear algebraic equation in $C_{Z}$ which can be solved easily to get $C_{Z}{ }^{(w t)}$.

\section{Concluding remarks}

This paper has shown how the use of the Momentum-Impulse theorem allows the derivation of physically-based extrapolations of opening shock test data, effectively doubling the range of mass ratios over which predictions can be made. Here the theorem was generalized in order to include the mission profiles of CPAS parachute systems involving (near) vertical trajectories and heavy, draggy payloads. The approach is detailed enough to reveal the role of forebody drag in partly dissipating air flow energy that would have otherwise been used in the inflation process itself. Interestingly, one of the authors has investigated such effects from a different approach, through a statistical analysis of measured drag in the presence of different wakes [14].

Although encouraging, the results are not definitive given some of the assumptions that need to be further investigated. An important - and so far unmentioned - assumption has been the explicit omission of aero-elastic effects that could amplify the value of $C_{k}$ [15]. The extrapolations obtained here should include those implicitly at least since the measured opening shock factor values used in Eq. 13 already incorporate them. It is just that the load amplification factor [15] that result is assumed to be the same at all $Z$ and $R_{m}$, something that is far from obvious. Another assumption has been the use of polynomial $J(Z)$ of Eqs. 6a and 9, which has originally been constructed from test data collected on unreefed low- and high porosity parachutes of diameters in the range of 15 to $30 \mathrm{ft}$ [5]. While the $5 \mathrm{~m}-\mathrm{D}_{0}$ ribbon parachute used in reference [5] is commensurate in size and porosity to the CPAS drogues, no data exist - both wind tunnel and test drop -on a ringsail design that would approach the design of the CPAS Mains. Given their impractical large size for wind tunnel investigations, using a $\sim 30 \%$ scale model could start the process of confirming $J(Z)$ as the correct scaling function for this type of parachute.

Finally, unmentioned here has been the analysis of the disreefing stages carried out by both CPAS Drogues and Mains towards the end of their inflation sequence(s). (Following $1^{\text {st }}$ stage inflation, both parachutes disreef into a $2^{\text {nd }}$ reefed constraint; this, in turns, is followed by another disreef into full-open). In principle the Momentum-Impulse theorem should provide the basis for constructing an extrapolation scheme that would be similar to the one described here [5]. The uncertainty rests again with the form of the $J(Z)$ polynomial, which might turn out different from the form used in this paper ( $1^{\text {st }}$ reefed stage inflation). In a most fundamental way, reefed and unreefed inflation, which begin in an un-pressurized state, differ from disreefing inflation which always begins in a fully pressurized state.

\section{ACKNOWLEDGMENTS}

The work by JP was initially supported by funding from JETS contract EN30125LEF.

\section{REFERENCES}

[1] T. W. Knacke, Parachute Recovery Systems Design Manual; Para Publishing (Santa Barbara, CA 1992).

[2] Wolf, D., "Opening Shock"; paper AIAA-99-1702, 15th CEAS/AIAA Aerodynamic Decelerator Systems Technology Conference, Toulouse, France, 8-11 June 1999.

[3] Potvin, J. and Peek, G.; “Testing without Load Cells - Can Opening Shock Be Estimated from Video data only?" Paper AIAA-2007-2551 presented at the 19th AIAA Aerodynamic Decelerator Systems Technology Conference and Seminar, 21 - 24 May 2007, Williamsburg, VA.

[4] Potvin, J.; "Universality Considerations for Graphing Parachute Opening Shock Factor Versus Mass Ratio "; J. Aircraft Vol. 44, No. 2, pp. 528 - 538, 2007.

[5] Potvin, J., and Peek, G.; "Peak Load of a Drogue: Applying the Momentum-Impulse Theorem to Infinite Mass Inflation". Paper AIAA-2015-2181. Presented at the 23th AIAA Aerodynamic Decelerator Systems Technology Conference and Seminar, Daytona Beach, FL, March 30 - April 2, 2015.

[6] Taylor, AP, Machin, R., Royall, P., and Sinclair, R. "Developing the Parachute System for NASA's Orion: An Overview at Inception", 19th AIAA Aerodynamic Decelerator Systems Technology Conference and Seminar, Aerodynamic Decelerator Systems Technology Conference

[7] Morris, A. L., Bledsoe, K. J., Fraire, U., et al., "Summary of CPAS Gen II Testing Analysis Results". Paper AIAA- 20112585. Presented at the 21 st AIAA Aerodynamic Decelerator Systems Technology Conference and Seminar, Dublin, Ireland, May 2011. 
[8] Ray, E.S.; "Reconstruction of Orion EDU Parachute Inflation Loads". Paper AIAA-2013-1260. Presented at the 22th AIAA Aerodynamic Decelerator Systems Technology Conference and Seminar, Daytona Beach, FL, March 25-28, 2013.

[9] Romero, L.M. and Ray, E.S.; “Application of Statistically Derived CPAS Parachute Parameters”. Paper AIAA-20131266. Presented at the 22th AIAA Aerodynamic Decelerator Systems Technology Conference and Seminar, Daytona Beach, FL, March 25-28, 2013.

[10] Potvin, J., "Updating and Upgrading the World's Database on the Opening Shock Factor Ck". Paper AIAA-2009-2905 presented at the 20th AIAA Aerodynamic Decelerator Systems Technology Conference and Seminar, 4 - 7 May 2009, Seattle, WA.

[11] Barnard, G. A.; "The Effect of Extreme Altitude of Parachute Filling Distance"; AIAA-93-1207; 12th AIAA Aerodynamic Decelerator Systems Technology Conference and Seminar (RAeS/AIAA) London, England, May 10-13, 1993.

[12] Lingard, J. S.; "A Semi-empirical Theory to Predict the Load-time History of an Inflating Parachute"; AIAA84-0814, 8th AIAA Aerodynamic Decelerator and Balloon Technology Conference, 1984, Hyannis, MA, April 2-4, 1984.

[13] Wolf, D. "Parachute Opening Shock". Lecture in H.G. Heinrich Parachute Systems Short Course, June 6 - 10 , 2016, Renaissance Portsmouth Hotel \& Waterfront Conference Center, Portsmouth, VA.

[14] Ray, E. S., "Test Vehicle Forebody Wake Effects on CPAS Parachutes". Presented at the 24th AIAA Aerodynamic Decelerator Systems Technology Conference and Seminar, Denver, CO, June 5 - 9, 2017.

[15] Wolf, D. and Fallon, E.; "Development of Parachute Opening Shock Factor Models for Ares First stage Parachute Recovery System". Paper AIAA-2011-2555. Presented at the 21st AIAA Aerodynamic Decelerator Systems Technology Conference and Seminar, Dublin, Ireland, May 2011,

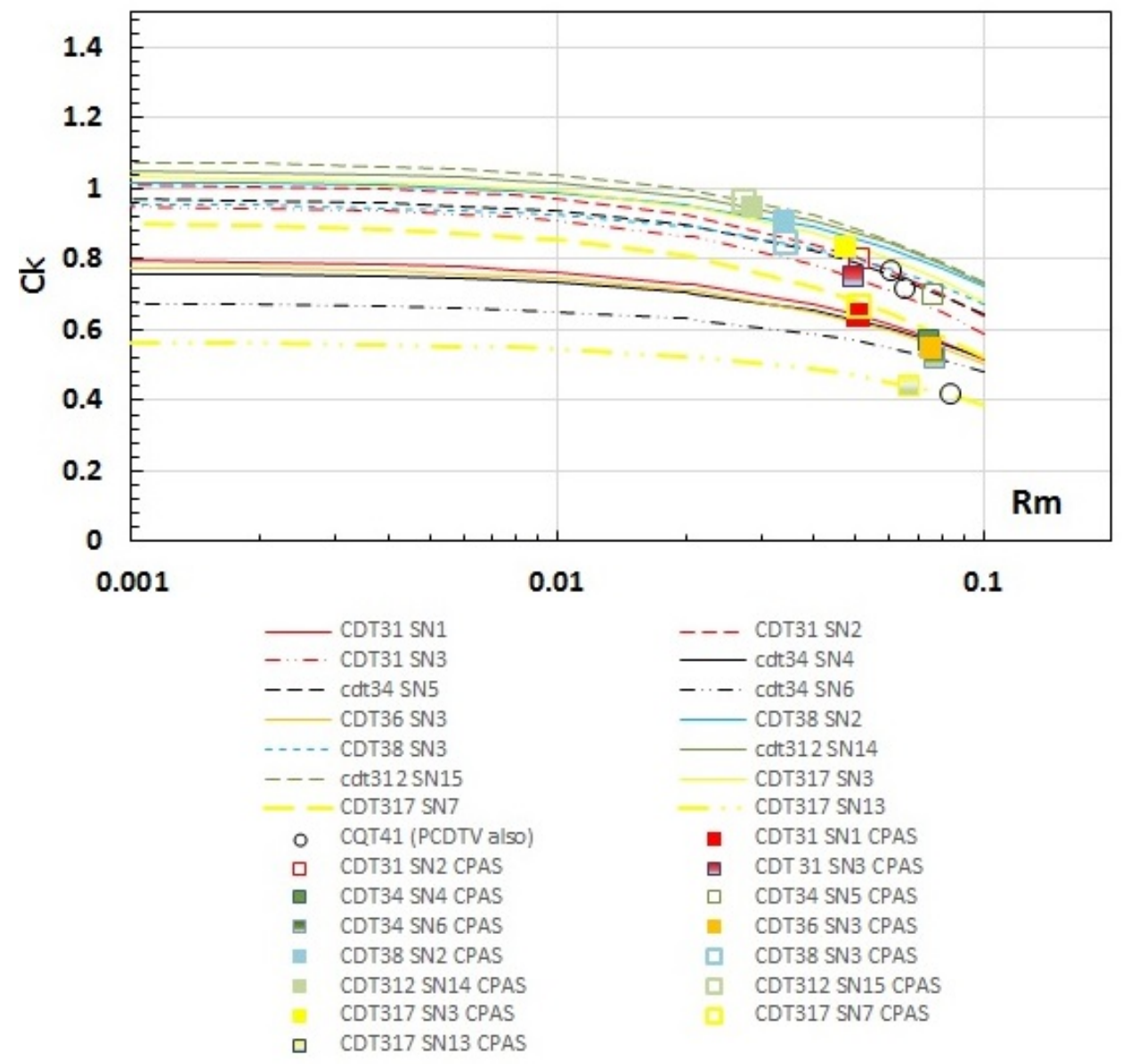

Figure 7. Extrapolations obtained from Eqs. 8 - 10, as applied to CPAS Mains (1 ${ }^{\text {st }}$ stage inflation) trailing the PCDTV. The extrapolation curves are represented by the continuous, dashed and dot-dashed lines, also traced with the color of the corresponding test drop. (Both should overlap at the test drop value of the mass ratio). The circles correspond to the CPAS-derived $\mathrm{C}_{\mathrm{k}}$ and $\mathrm{R}_{\mathrm{m}}$ of the first qualification test (CQT-4-1), also a PCDTV drop. 


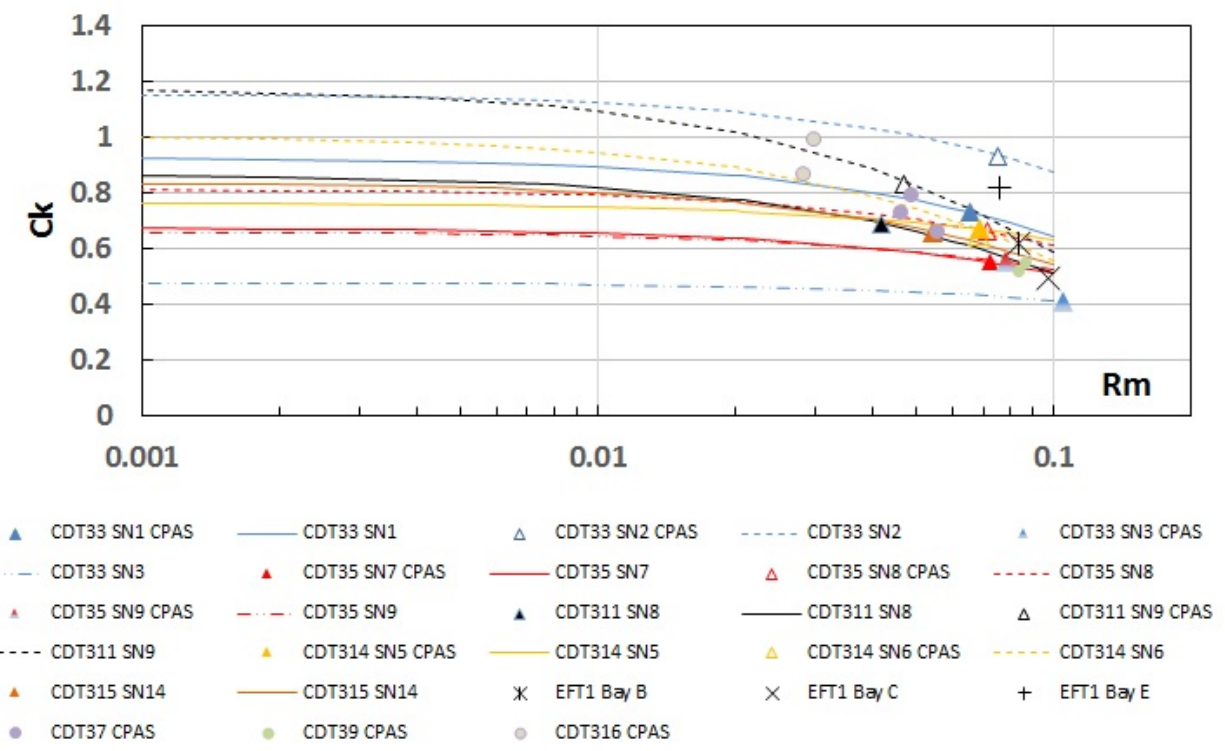

Figure 8. Extrapolations obtained from Eqs. 8 - 10, as applied to CPAS Mains ( $1^{\text {st }}$ stage) trailing the PTV. The extrapolations and test data appear as in figure 7. The time, cross and burst symbols correspond to the CPAS-derived $C_{k}$ and $R_{m}$ of the first capsule test of December 2014 (EFT-1). EDU test drops CDT-3-7, -9 and -16 (grey circles) were not used for generating extrapolations and appear as single CPAS-generated data.

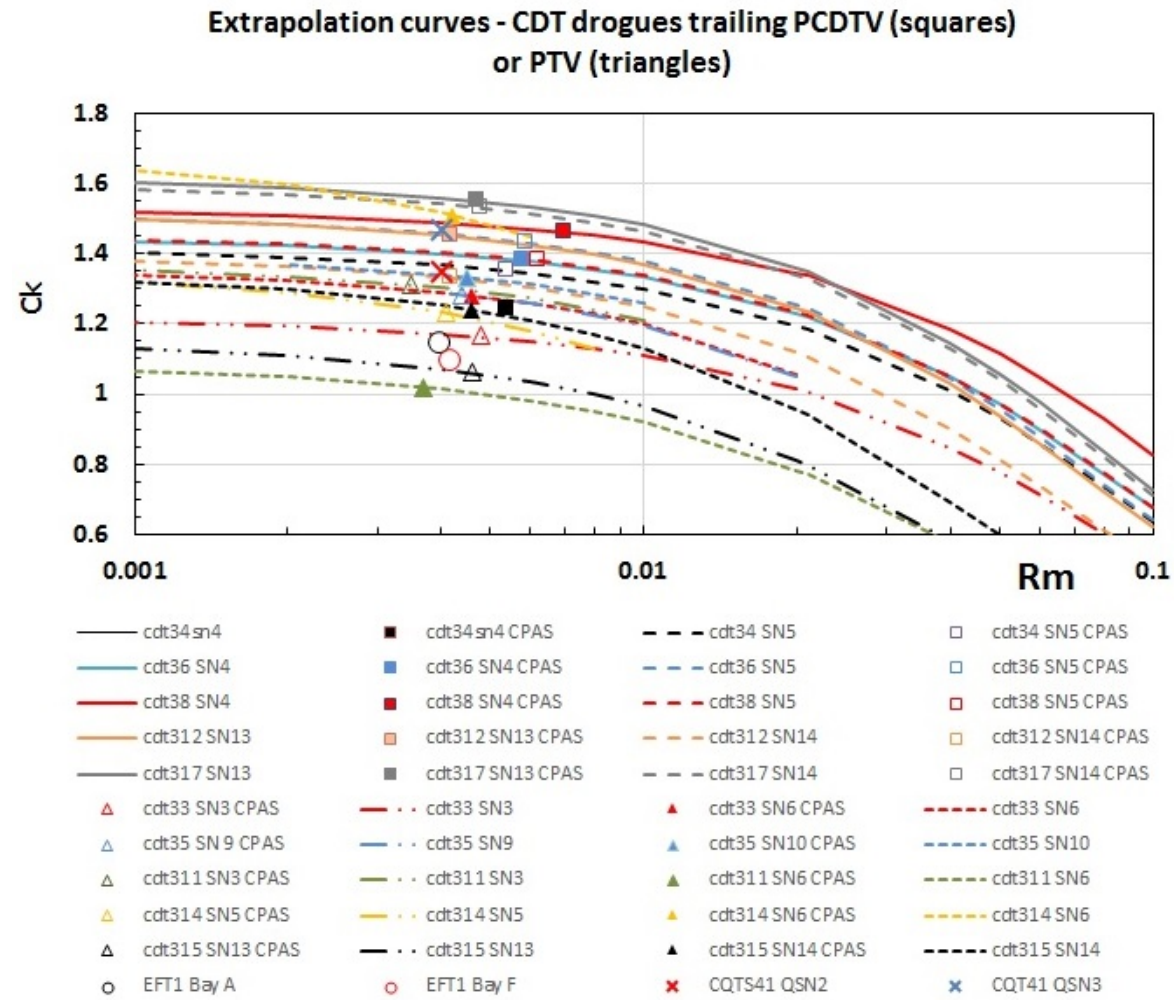

Figure 9. Extrapolations obtained from Eqs. 8 - 10, as applied to CPAS Drogues $\left(1^{\text {st }}\right.$ stage) trailing the PCDTV (squares) and PTV (triangles). The extrapolations and test data appear as in figure 7. The circles correspond to the CPAS-derived $C_{k}$ and $R_{m}$ of the first capsule test of December 2014 (EFT-1) and the "times" to the data of the first qualification test (CQT-4-1), also a PCDTV drop. 
Table 1. Analysis of the Mains' $1^{\text {st }}$ stage inflation while decelerating a PCDTV. CPAS data are printed in black and quantities calculated from this data printed in red. The value of $H$ (printed in blue) has been discussed in Section III.B. Data marked by a double asterisk are deemed unreliable as the linearized $J(Z)$ (with only two terms) differs from the full $J(Z)$ (Eq. 9) by more than $5 \%$ at the $R_{m}$-value of the test. Inputs marked as "NGD" were neglected owing to their insignificance in the calculation. Note that the fill time constant $\left(n_{\text {fill }}\right)$ marks the time between the beginning of inflation (not line-stretch necessarily) and the time of peak drag. As such these values may differ from those of other CPAS documents. In all tests, the fall trajectory's flight angle always yielded $\langle\cos \gamma>\sim 1$.

\begin{tabular}{|c|c|c|c|c|c|c|c|c|c|c|c|c|c|}
\hline $\begin{array}{c}C D T \\
-3\end{array}$ & $S / N$ & $\mathrm{H}$ & $\begin{array}{c}\text { Dref } \\
\mathrm{ft}\end{array}$ & $\begin{array}{c}V_{\text {intial }} \\
\mathrm{ft} / \mathrm{s}\end{array}$ & $\begin{array}{c}\mathbf{R}_{\mathrm{m}} \text { (Eqs. } \\
2 \text { \& 3) }\end{array}$ & $\begin{array}{c}\mathbf{n}_{\text {fill }} \\
\text { sect. } \\
\text { II.A }\end{array}$ & $\begin{array}{c}S_{D} C_{D} \\
\text { chute } \\
\text { (steady) } \\
\mathrm{ft}^{2}\end{array}$ & $C_{k}$ & $\begin{array}{l}\text { Ichute } \\
\text { Eq. } 15\end{array}$ & $\begin{array}{c}S^{S} C_{D}\left(\mathrm{ft}^{2}\right) \\
\text { Forebody } \\
\text { (share) } \\
\left(\text { at } \mathrm{t}=\mathrm{t}_{\mathrm{i}}\right)\end{array}$ & $\begin{array}{l}\text { Iforebody } \\
\text { Eq. } 11\end{array}$ & $\begin{array}{c}\text { Cz Eq. } 13 \\
\text { (linearized); } \\
\text { negative } \\
\text { root }\end{array}$ & $\mathbf{Z}$ \\
\hline \multirow[t]{3}{*}{-1} & 1 & 0.5 & 22.9 & 272.4 & 0.0570 & 23.50 & 326.9 & 0.64 & 0.50 & NGD & NGD & 0.2045 & 0.0052 \\
\hline & 2 & 0.5 & 22.9 & 272.4 & 0.0510 & 18.58 & 330.5 & 0.80 & 0.51 & NGD & NGD & 0.2763 & 0.0387 \\
\hline & 3 & 0.5 & 22.9 & 272.4 & 0.0492 & 19.78 & 308.1 & 0.75 & 0.52 & NGD & NGD & 0.2709 & 0.0336 \\
\hline \multirow[t]{3}{*}{-4} & 4 & 0.5 & 25.1 & 290.6 & 0.0740 & 21.90 & 412.0 & 0.57 & 0.50 & NGD & NGD & 0.1951 & 0.0534 \\
\hline & 5 & 0.5 & 25.1 & 290.6 & 0.0758 & 18.90 & 431.9 & 0.70 & 0.49 & NGD & NGD & 0.2449 & 0.0851 \\
\hline & 6 & 0.5 & 25.1 & 290.6 & 0.0762 & 21.90 & 436.1 & 0.52 & 0.51 & NGD & NGD & 0.1712 & 0.0382 \\
\hline \multirow[t]{3}{*}{-6} & 1 & 0.5 & 25.4 & 313.9 & 0.0657 & 14.93 & 315.0 & 0.81 & 0.53 & NGD & NGD & $0.4117 * *$ & $0.1400 * *$ \\
\hline & 2 & 0.5 & 25.4 & 313.9 & 0.0908 & 43.12 & 602.0 & 0.43 & 0.55 & NGD & NGD & $0.1690 * *$ & $0.1521^{* *}$ \\
\hline & 3 & 0.5 & 25.4 & 313.9 & 0.0749 & 21.88 & 409.3 & 0.55 & 0.54 & NGD & NGD & 0.2242 & 0.0928 \\
\hline \multirow[t]{2}{*}{-8} & 2 & 0.5 & 22.6 & 326.4 & 0.0336 & 13.61 & 331.5 & 0.91 & 0.48 & NGD & NGD & 0.2800 & 0.0176 \\
\hline & 3 & 0.5 & 22.6 & 326.4 & 0.0340 & 16.38 & 339.9 & 0.85 & 0.45 & NGD & NGD & 0.2391 & 0.0107 \\
\hline \multirow[t]{2}{*}{-12} & 14 & 0.5 & 21.4 & 304.4 & 0.0283 & 15.10 & 327.9 & 0.95 & 0.48 & NGD & NGD & 0.2702 & 0.0016 \\
\hline & 15 & 0.5 & 21.4 & 304.4 & 0.0273 & 14.60 & 306.0 & 0.97 & 0.49 & NGD & NGD & 0.2929 & 0.0041 \\
\hline \multirow[t]{3}{*}{-17} & 3 & 0.5 & 22.9 & 350.7 & 0.0470 & 13.68 & 256.6 & 0.84 & 0.50 & NGD & NGD & 0.3434 & 0.0694 \\
\hline & 7 & 0.5 & 22.9 & 350.7 & 0.0508 & 21.43 & 300.0 & 0.67 & 0.54 & NGD & NGD & 0.2871 & 0.0921 \\
\hline & 13 & 0.5 & 22.9 & 350.7 & 0.0669 & 31.01 & 520.7 & 0.44 & 0.55 & NGD & NGD & 0.1319 & 0.0440 \\
\hline
\end{tabular}

Table 2. Analysis of the Mains' $1^{\text {st }}$ stage inflation while decelerating a PTV. Same symbol convention as in Table 1.

\begin{tabular}{|c|c|c|c|c|c|c|c|c|c|c|c|c|c|}
\hline $\begin{array}{c}\text { CDT } \\
-3\end{array}$ & $S / N$ & $\mathbf{H}$ & $\begin{array}{c}D_{\text {ref }} \\
\mathrm{ft}\end{array}$ & $\begin{array}{l}V_{\text {intial }} \\
\mathrm{ft} / \mathrm{s}\end{array}$ & $\begin{array}{c}\mathbf{R}_{\mathbf{m}} \text { (Eqs. } \\
2 \text { \& 3) }\end{array}$ & $\mathbf{n}_{\text {fill }}$ & $\begin{array}{c}S_{D} \\
\text { chute } \\
\text { (steady) } \\
\mathrm{ft}^{2}\end{array}$ & $C_{k}$ & $\begin{array}{l}\text { I chute } \\
\text { Eq. } 15\end{array}$ & $\begin{array}{c}S^{S} C_{D}\left(\mathrm{ft}^{2}\right) \\
\text { Forebody } \\
\text { (share) } \\
\left(\text { at } \mathrm{t}=\mathrm{t}_{\mathrm{i}}\right)\end{array}$ & $\begin{array}{l}\text { Iforebody } \\
\text { Eq. } 11\end{array}$ & $\begin{array}{c}\text { Cz Eq. } 13 \\
\text { (linearized); } \\
\text { negative } \\
\text { root }\end{array}$ & Z \\
\hline \multirow[t]{3}{*}{-3} & 1 & 0.5 & 19.5 & 257.2 & 0.0653 & 20.8 & 275.5 & 0.73 & 0.406 & 36.5 & 0.619 & 0.1948 & 0.0336 \\
\hline & 2 & 0.5 & 22.6 & 257.2 & 0.0755 & 11.1 & 367.4 & 0.93 & 0.437 & 48.7 & 0.619 & 0.2804 & 0.0565 \\
\hline & 3 & 0.5 & 31.2 & 257.2 & 0.1048 & 12.2 & 708.1 & 0.41 & 0.530 & 93.9 & 0.619 & 0.1319 & -0.0082 \\
\hline \multirow[t]{3}{*}{-5} & 7 & 0.5 & 24.0 & 256.8 & 0.0724 & 22.6 & 418.0 & 0.55 & 0.417 & 44.5 & 0.854 & 0.1372 & -0.0200 \\
\hline & 8 & 0.5 & 23.7 & 256.8 & 0.0715 & 13.3 & 407.6 & 0.66 & 0.549 & 43.4 & 0.854 & 0.2412 & 0.0377 \\
\hline & 9 & 0.5 & 26.0 & 256.8 & 0.0784 & 13.7 & 489.8 & 0.55 & 0.536 & 52.1 & 0.854 & 0.1876 & 0.0138 \\
\hline \multirow[t]{2}{*}{-11} & 8 & 0.5 & 20.8 & 273.5 & 0.0418 & 19.0 & 250.4 & 0.69 & 0.561 & 41.7 & 1.113 & 0.3116 & 0.0387 \\
\hline & 9 & 0.5 & 24.2 & 271.6 & 0.0471 & 17.8 & 319.3 & 0.83 & 0.572 & 53.3 & 1.113 & 0.4399 & 0.0904 \\
\hline \multirow[t]{2}{*}{-14} & 5 & 0.5 & 25.3 & 260.7 & 0.0690 & 10.1 & 442.8 & 0.67 & 0.473 & 55.0 & 0.871 & 0.2083 & 0.0121 \\
\hline & 6 & 0.5 & 25.2 & 260.6 & 0.0687 & 20.1 & 439.6 & 0.65 & 0.552 & 54.3 & 0.871 & 0.2575 & 0.0578 \\
\hline \multirow[t]{2}{*}{-15} & 14 & 0.5 & 32.2 & 267.8 & 0.0544 & 21.2 & 667.7 & 0.66 & 0.535 & 122.1 & 0.655 & 0.2290 & -0.0210 \\
\hline & 15 & 0.5 & 19.1 & 267.6 & 0.0323 & 27.8 & 235.1 & 1.10 & 0.488 & 42.9 & 0.655 & $* *$ & $* *$ \\
\hline
\end{tabular}


Table 3. Analysis of the drogues' $1^{\text {st }}$ stage inflation while decelerating a PCDTV. Same symbol convention as in Table 1. Note that SN4 skipped to full open during CDT-3-8.

\begin{tabular}{|c|c|c|c|c|c|c|c|c|c|c|c|c|c|}
\hline $\begin{array}{c}\text { CDT } \\
-3\end{array}$ & $\mathbf{S} / \mathbf{N}$ & H & $\begin{array}{c}D_{\text {ref }} \\
\mathrm{ft}\end{array}$ & $\begin{array}{c}V_{\text {intial }} \\
\mathrm{ft} / \mathrm{s}\end{array}$ & $\begin{array}{c}\mathbf{R}_{\mathrm{m}} \text { (Eqs. } \\
2 \text { \& 3) }\end{array}$ & $\mathbf{n}_{\text {fill }}$ & $\begin{array}{c}S C_{D} \\
\text { chute } \\
\text { (steady) } \\
\mathrm{ft}^{2}\end{array}$ & $C_{k}$ & $\begin{array}{l}\text { Ichute } \\
\text { Eq. } 15\end{array}$ & $\begin{array}{c}S C_{D}\left(\mathrm{ft}^{2}\right) \\
\text { Forebody } \\
(\text { share) } \\
\left(\text { at } \mathrm{t}=\mathrm{t}_{\mathrm{i}}\right)\end{array}$ & $\begin{array}{c}\text { Iforebody } \\
\text { Eq. } 11\end{array}$ & $\begin{array}{c}\mathrm{C}_{\mathrm{z}} \mathrm{Eq} .13 \\
\text { (linearized); } \\
\text { negative } \\
\text { root }\end{array}$ & $\mathbf{Z}$ \\
\hline \multirow[t]{2}{*}{-1} & 5 & 1.8 & 15.6 & 275.3 & 0.0052 & 4.23 & 114.8 & 1.36 & 0.426 & $* *$ & $* *$ & $* *$ & $* *$ \\
\hline & 4 & 1.8 & 15.8 & 275.2 & 0.0054 & 5.57 & 120.1 & 1.45 & 0.378 & $* *$ & $* *$ & $* *$ & $* *$ \\
\hline \multirow[t]{2}{*}{-4} & 4 & 1.8 & 15.5 & 430.2 & 0.0054 & 5.27 & 118.3 & 1.24 & 0.647 & 16.3 & 1 & 0.642 & 0.0078 \\
\hline & 5 & 1.8 & 15.9 & 427.5 & 0.0054 & 5.28 & 118.5 & 1.35 & 0.444 & 16.3 & 1 & 0.485 & -0.0017 \\
\hline \multirow[t]{2}{*}{-6} & 4 & 1.8 & 16.7 & 481.4 & 0.0058 & 5.48 & 123.0 & 1.38 & 0.392 & 16.0 & 1 & 0.454 & 0.0031 \\
\hline & 5 & 1.8 & 15.0 & 484.6 & 0.0059 & 5.49 & 123.9 & 1.43 & 0.485 & 16.0 & 1 & 0.521 & 0.0100 \\
\hline \multirow[t]{2}{*}{-8} & 4 & 1.8 & 23.0 & 458.2 & 0.0070 & 3.98 & 163.1 & 1.46 & 0.335 & 18.0 & 1 & 0.488 & -0.0008 \\
\hline & 5 & 1.8 & 16.3 & 454.5 & 0.0062 & 5.86 & 126.1 & 1.38 & 0.378 & 18.0 & 1 & 0.423 & 0.0009 \\
\hline \multirow[t]{2}{*}{-12} & 13 & 1.8 & 15.8 & 569.5 & 0.0042 & 7.56 & 122.0 & 1.45 & 0.343 & 16.5 & 1 & 0.394 & 0.0012 \\
\hline & 14 & 1.8 & 15.9 & 569.9 & 0.0042 & 5.73 & 123.5 & 1.33 & 0.554 & 16.5 & 1 & 0.593 & 0.0094 \\
\hline \multirow[t]{2}{*}{-17} & 13 & 1.8 & 15.7 & 544.5 & 0.0047 & 5.20 & 118.5 & 1.55 & 0.403 & 17.2 & 1 & 0.509 & 0.0064 \\
\hline & 14 & 1.8 & 15.9 & 544.4 & 0.0048 & 5.13 & 123.6 & 1.53 & 0.424 & 17.2 & 1 & 0.522 & 0.0071 \\
\hline
\end{tabular}

Table 4. Analysis of the drogues' $1^{\text {st }}$ stage inflation while decelerating a PTV. Same symbol convention as in Table 1.

\begin{tabular}{|c|c|c|c|c|c|c|c|c|c|c|c|c|c|}
\hline $\begin{array}{c}\text { CDT } \\
-3\end{array}$ & $\mathbf{S} / \mathbf{N}$ & H & $\begin{array}{c}\text { Dref } \\
\mathrm{ft}\end{array}$ & $\begin{array}{c}V_{\text {intial }} \\
\mathrm{ft} / \mathrm{s}\end{array}$ & $\begin{array}{c}\mathbf{R}_{\mathrm{m}} \text { (Eqs. } \\
2 \text { \& 3) }\end{array}$ & $n_{\text {fill }}$ & $\begin{array}{c}S C_{D} \\
\text { chute } \\
\text { (steady) } \\
\mathrm{ft}^{2}\end{array}$ & $C_{k}$ & $\begin{array}{l}\text { Ichute } \\
\text { Eq. } 15\end{array}$ & $\begin{array}{l}\mathrm{SC}_{D}\left(\mathrm{ft}^{2}\right) \\
\text { Forebody } \\
(\text { share) } \\
\left(\text { at } \mathrm{t}=\mathrm{t}_{\mathrm{i}}\right)\end{array}$ & $\begin{array}{c}\text { Iforebody } \\
\text { Eq. } 11\end{array}$ & $\begin{array}{c}\text { Cz Eq. } 13 \\
\text { (linearized); } \\
\text { negative } \\
\text { root }\end{array}$ & $\mathbf{Z}$ \\
\hline \multirow[t]{2}{*}{-3} & 3 & 1.8 & 16.2 & 266.8 & 0.0048 & 4.61 & 125.8 & 1.16 & 0.468 & 67.5 & 1 & 0.599 & -0.0368 \\
\hline & 6 & 1.8 & 16.3 & 266.3 & 0.0046 & 3.93 & 114.1 & 1.28 & 0.568 & 67.5 & 1 & 0.974 & -0.0210 \\
\hline \multirow[t]{2}{*}{-5} & 9 & 1.8 & 15.1 & 270.2 & 0.0044 & 5.72 & 113.8 & 1.28 & 0.362 & 89.3 & 1 & 0.690 & -0.0370 \\
\hline & 10 & 1.8 & 15.7 & 270.1 & 0.0045 & 4.81 & 122.5 & 1.33 & 0.353 & 89.3 & 1 & 0.648 & -0.0340 \\
\hline \multirow[t]{2}{*}{-11} & 3 & 1.8 & 15.7 & 337.3 & 0.0035 & 5.78 & 108.1 & 1.31 & 0.384 & 82.1 & 0.762 & 0.648 & -0.0225 \\
\hline & 6 & 1.8 & 15.1 & 340.6 & 0.0037 & 6.30 & 118.7 & 1.02 & 0.690 & 90.2 & 0.762 & 0.791 & -0.0141 \\
\hline \multirow[t]{2}{*}{-14} & 5 & 1.8 & 15.8 & 415.3 & 0.0041 & 5.16 & 112.4 & 1.23 & 0.448 & 103.4 & 0.986 & 1.322 & 0.0229 \\
\hline & 6 & 1.8 & 15.4 & 415.9 & 0.0042 & 6.49 & 115.0 & 1.51 & 0.360 & 105.8 & 0.986 & 1.169 & 0.0230 \\
\hline \multirow[t]{2}{*}{-15} & 13 & 1.8 & 15.8 & 266.7 & 0.0046 & 5.01 & 117.8 & 1.06 & 0.552 & 99.4 & 1 & 1.064 & -0.0200 \\
\hline & 14 & 1.8 & 15.0 & 267.3 & 0.0046 & 4.97 & 115.4 & 1.24 & 0.499 & 99.4 & 1 & 1.051 & -0.0171 \\
\hline
\end{tabular}

